\section{Morphological and immunohistochemical study of ovarian and tubal dysplasia associated with tamoxifen}

\author{
G. Chene, ${ }^{1,2}$ N. Radosevic-Robin, ${ }^{1}$ \\ A.S. Tardieu, ${ }^{1}$ A. Cayre, ${ }^{1}$ I. Raoelfils, ${ }^{1}$ \\ P. Dechelotte, ${ }^{3}$ J. Dauplat, ${ }^{4}$ \\ F. Penault-Llorca'
}

'Department of Histopathology, Centre Jean Perrin, ERTICA Research Team, EA

4677, Clermont-Ferrand

2Department of Gynecology, HFME, CHU

Lyon

${ }^{3}$ Department of Histopathology, CHU

Estaing, Clermont-Ferrand

${ }^{4}$ Department of Surgery, Centre Jean

Perrin, Clermont-Ferrand, France

\section{Abstract}

Ovarian epithelial dysplasia was initially described in material from prophylactic oophorectomies for BReast CAncer gene (BRCA) mutation. Similar histopathological abnormalities have been revealed after ovulation stimulation. Given that tamoxifen (TAM) has a clomid-like effect and is sometimes used to induce ovulation, we studied the morphological features and immunohistochemical expression patterns of neoplasia-associated markers in adnexectomies previously exposed to TAM for breast cancer. We blindly reviewed 173 histopathological slides of adnexectomies according to three groups - oophorectomies associated with TAM exposure $(\mathrm{n}=42)$, oophorectomies associated with clomiphene exposure $(n=15)$ and a spontaneously fertile non cancerous control group $(\mathrm{n}=116)$. Morphological features (with an ovarian and tubal dysplasia scoring system) and immunohistochemical expression patterns of $\mathrm{Ki}-67$, p53 and Aldehyde dehydrogenase 1 (ALDH1 is an enzyme significantly associated with earlystage ovarian cancer) were evaluated and correlated. Mean tubal dysplasia score was significantly higher in the TAM group and clomiphen group than in controls (respectively 7.8 vs 3.5 , $\mathrm{P}<0.007$ and 6.8 vs $3.5, \mathrm{P}=0.008$ ). There is no statistical difference for the ovarian score in TAM group in comparison with the control group whereas we found a significant score for clomiphen group (6.5, $\mathrm{P}=0.009)$. Increased ALDH1 expression was observed in the two exposed group whereas expression patterns of Ki67 and p53 were moderate. Interestingly, ALDH1 expression was low in non-dysplastic epithelium, high in dysplasia, and constantly low in the two carcinoma.
Furthemore, we confirm our previous results showing that ALDH1 may be a useful tissue biomarker in the subtle histopathological diagnosis of tubo-ovarian dysplasia.

\section{Introduction}

Tamoxifen (TAM) is commonly used as an adjuvant therapy in the antihormonal treatment of choice in premenopausal breast cancer patients. It is a non-steroidal selective estrogen receptor modulator (SERM) and, like clomiphene citrate, it has also been used to induce ovulation. It is also known that Tamoxifen increases the incidence of ovarian follicular cysts., ${ }^{1,2}$ On the other hand, histopathological study of material from prophylactic oophorectomies performed for a genetic predisposition to ovarian cancer can reveal cytological and architectural abnormalities considered to be pre-cancerous manifestations. These abnormalities are termed dysplasia by analogy with the pre-invasive lesions described for the genital tract (vulva, vagina, cervix, endometrium)..$^{3-9}$ Similarly, serous tubal intraepithelial lesions (STILs, a spectrum of epithelial changes ranging from normal appearing tubal epithelium to lesions with cytologic atypia and dysplasia) have recently been described in prophylactically removed Fallopian tubes of women predisposed to develop ovarian cancer. ${ }^{10,11}$ Moreover, several studies have found similar ovarian dysplasia lesions after stimulation of ovulation in infertile patients. ${ }^{12-14}$ We sought to identify dysplasia lesions in salpingo-oophorectomies associated with Tamoxifen and to assess the expression of proliferation and differentiation-related proteins (Ki67, p53, and Aldehyde dehydrogenase 1 or ALDH1), ${ }^{2,3}$ To the best of our knowledge, this is the first study to assess tubo-ovarian lesions under TAM on the one hand, and on the other to underline the accuracy of ALDH1 staining as for tubo-ovarian precursor lesions.

\section{Materials and Methods}

\section{Patients}

Between January 1995 and December 2000, we selected three groups of patients:

Group A: salpingo-oophorectomies associated with tamoxifen exposure (TAM group). We included 42 removed ovaries and tubes associated with tamoxifen exposure for previous breast cancer without BRCA mutation. Two occult ovarian carcinomas were excluded from the dysplasia evaluation study because morphological dysplasia analysis was designed to
Correspondence: Gautier Chene, Department of Histopathology, Centre Jean Perrin, ClermontFerrand, 63000 France.

Tel. +33.6.07081786 - Fax: +33.4.77828956.

E-mail: chenegautier@yahoo.fr

Key words: ovarian carcinogenesis, ovarian dysplasia, prophylactic oophorectomy, ALDH1, p53.

Conflict of interests: the authors declare no conflict of interests.

Funding: La ligue contre le cancer Foundation.

Received for publication: 29 July 2013.

Accepted for publication: 3 March 2014.

This work is licensed under a Creative Commons Attribution NonCommercial 3.0 License (CC BYNC 3.0).

(C) Copyright G. Chene et al., 2014

Licensee PAGEPress, Italy

European Journal of Histochemistry 2014; 58:2251 doi:10.4081/ejh.2014.2251

identify potential premalignant lesions.

Group B: salpingo-oophorectomies associated with clomiphene citrate. We selected an infertile population who had adnexectomies after ovulation induction by clomiphene several years later and whose ovaries and tubes were reported as normal on routine histological examination: 15 cases were included.

Group C: Control group. We selected a spontaneously non cancerous and fertile population of matching age, with no personal nor family history of gynaecologic neoplasia (breast, ovary, endometrium), who underwent adnexectomy for which the histopathological examination concluded that the ovaries and tubes did not show any sign of cancerous or borderline pathology or salpingitis: 116 controls were included in the study.

\section{Histopathological criteria}

\section{Evaluation of morphological features}

Morphological studies were processed on 3 micron paraffin sections stained with standard haematoxylin phloxin safran (HPS). The number of sections available for review for each case (ovary and tube) ranged from 7 to 11 in all groups.

The histopathology slides for the 40 patients who had used Tamoxifen, 15 patients who had used Clomiphene citrate and the 116 control were all scored blinded by two spcialists in gynecopathology (FPL and IR) who were specialists in onco-gynaecology pathology, in order to obtain an average score. As initialy described in ovarian dysplasia studies, ${ }^{12,13,15}$ when several slides were available, the one with the highest dysplasia score was retained. 
For the ovarian cystectomies, the slides were read to confirm the histopathological diagnosis and to inspect associated ovarian tissue to determine its dysplasia score. Absence of associated ovarian tissue was an exclusion criterion. In the event of obvious disagreements between pathologists, a further examination was carried out to reach a consensus.

\section{Ovarian dysplasia}

There is no consensual dysplasia scoring system, as the histopathological characteristics of dysplasia are difficult and subtle to determine. The definition of ovarian dysplasia was thus based on cytological and architectural criteria described in previous studies of ovarian dysplasia, i.e., dysplasia found in prophylactic oophorectomy for BRCA mutations, ${ }^{3-5}$ in areas adjacent to Stage 1 ovarian carcino$\mathrm{ma},{ }^{6,7}$ in the contralateral ovary in case of unilateral ovarian cancer, 8,9 and in relation to ovulation induction. ${ }^{12}$ We pooled the criteria to design an eleven criteria (listed below) scoring system used in our previous studies on the relationship between ovarian dysplasia, ovulation induction, and genetic risk: ${ }^{13-15}$

- epithelial pseudostratification

- epithelial proliferation : pilling up the cells, increased cellularity and Ki67 expression, as previously published ${ }^{13-16}$

- surface papillomatosis

- irregular nuclear chromatine pattern

- irregular nuclear contour

- cellular pleiomorphism

- increase in nuclear size (nuclear-cytoplasmic ratio and comparison to the normal nuclei)

- inclusion cysts (presence of more than three contiguous cysts)

- deep epithelial invaginations

- psammoma

- stromal hyperplasia.

In each case, the abnormal areas were scored between 0 and 2 ( 0 , normal; 1 , moderately abnormal; 2 , severely abnormal), whether located on the surface or in an inclusion cyst. An overall dysplasia ovarian score was then obtained for each patient by simply adding the scores for each of the 11 items (total range: 0 to 22$)$.

\section{Tubal dysplasia}

As for the ovary, the difficulty of analysing tubal dysplasia can be explained by the lack of well established morphological criteria for precursors of Fallopian tube carcinoma. Our definition was based on previous studies of tubal precursor lesions (named Serous Tubal Intraepithelial Lesions, STILs) described in Fallopian tubes from patients with a genetic risk (prophylactic oophorectomy for BRCA1/2 mutations), and we designed a scoring system with seven histopathological criteria: $:^{10,11,16-18}$ - epithelial pseudostratification
- tufting

- loss of nuclear polarity

- increase in nuclear density

- nuclear atypia

- nucleomegaly

- loss of ciliation

In each case, the abnormal areas were scored between 0 and 2 ( 0 , normal; 1 , moderately abnormal; 2 , severely abnormal). An overall dysplasia tubal score was then obtained for each patient by simply adding the scores for each of the 7 items (total range: 0 to 14).

Table 1. Immunohistochemical characteristics.

\begin{tabular}{lccccc}
\hline Antibody & Clone & Manufacturer & Dilution & Incubation & Detection \\
\hline Ki67 & MIB-1 & DAKO & $1 / 100$ & $32 \mathrm{~min}$ & Ultraview \\
P53 & DO-7 & DAKO & $1 / 200$ & $32 \mathrm{~min}$ & Ultraview \\
\hline ALDH1 & 44/ALDH & BD Biosciences & $1 / 400$ & $60 \mathrm{~min}$ & Ultraview \\
\hline
\end{tabular}

Table 2. Comparison of respective frequencies of the eleven histopathologic abnormalities in our ovarian dysplasia scoring system.

\begin{tabular}{|c|c|c|c|c|}
\hline Histopathological items & $\begin{array}{l}\text { Group A } \\
(n=40)\end{array}$ & $\begin{array}{c}\text { Group B } \\
(n=15)\end{array}$ & $\begin{array}{l}\text { Group C } \\
(n=116)\end{array}$ & $\mathbf{P}$ \\
\hline Epithelial pseudostratification & $23(57.5 \%)$ & $10(66.6 \%)$ & $54(46.5 \%)$ & $\begin{array}{l}\mathrm{P} 1=0.240 \\
\mathrm{P} 2=0.032 \\
\mathrm{P} 3=0.750\end{array}$ \\
\hline Epithelial proliferation & $12(30 \%)$ & $11(73.3 \%)$ & $35(30.1 \%)$ & $\begin{array}{l}P 1=0.930 \\
P 2=0.002 \\
P 3=0.003\end{array}$ \\
\hline Surface papillomatosis & $14(35 \%)$ & $9(60 \%)$ & $27(23.2 \%)$ & $\begin{array}{l}P 1=0.1200 \\
P 2=0.0070 \\
P 3=0.0074\end{array}$ \\
\hline Irregular nuclear chromatine pattern & $13(32.5 \%)$ & $7(46.6 \%)$ & $21(18.1 \%)$ & $\begin{array}{c}\mathrm{P} 1=0.054 \\
\mathrm{P} 2=0.0072 \\
\mathrm{P} 3=0.07\end{array}$ \\
\hline Irregular nuclear contour & $7(17.5 \%)$ & $7(46.6 \%)$ & $35(30.1 \%)$ & $\begin{array}{l}P 1=0.371 \\
P 2=0.060 \\
P 3=0.0071\end{array}$ \\
\hline Cellular pleiomorphism & $13(32.5 \%)$ & $8(53.3 \%)$ & $36(31 \%)$ & $\begin{array}{l}\mathrm{P} 1=0.515 \\
\mathrm{P} 2=0.006 \\
\mathrm{P} 3=0.007\end{array}$ \\
\hline Increase in nuclear size & $5(12.5 \%)$ & $7(46.6 \%)$ & $22(18.9 \%)$ & $\begin{array}{l}P 1=0.5130 \\
P 2=0.0038 \\
P 3=0.0025\end{array}$ \\
\hline Inclusion cysts & $24(60 \%)$ & $10(66.6 \%)$ & $60(51.7 \%)$ & $\begin{array}{l}\mathrm{P} 1=0.196 \\
\mathrm{P} 2=0.12 \\
\mathrm{P} 3=0.82\end{array}$ \\
\hline Deep epithelial invaginations & $17(42.5 \%)$ & $13(86.6 \%)$ & $42(36.2 \%)$ & $\begin{array}{l}\mathrm{P} 1=0.324 \\
\mathrm{P} 2=0.012 \\
\mathrm{P} 3=0.019\end{array}$ \\
\hline Psammoma & $22(55 \%)$ & $6(40 \%)$ & $13(11.2 \%)$ & $\begin{array}{c}\mathrm{P} 1<0.001 \\
\mathrm{P} 2=0.0052 \\
\mathrm{P} 3=0.74\end{array}$ \\
\hline Stromal hyperplasia & $28(70 \%)$ & $13(86.6 \%)$ & $29(25 \%)$ & $\begin{array}{c}\mathrm{P} 1<0.0001 \\
\mathrm{P} 2<0.00001 \\
\mathrm{P} 3=0.24\end{array}$ \\
\hline
\end{tabular}

P1, statistical differences between group A and C; P2, statistical differences between group B and C; P3, statistical differences between group A and B.

\section{Evaluation of immunostaining}

Immunohistochemistry was performed on 3 micron sections, on silanised slides dried overnight at $56^{\circ} \mathrm{C}$. Ki67, P53 and ALDH1 immunostaining was performed with a BenchmarkXT immunostainer (Ventana Medical Systems, Illkirch, France) as indicated in Table 1. For Ki67 and P53, immunostaining was evaluated semiquantitatively and independently by two pathologists (IR, FPL) using a scoring protocol described in studies of immunohistochemistry and ovarian dyspla- 
sia: ${ }^{19}$ an immunoreactive score (IRS) ranging from 0 to 12 was defined as the product of staining intensity ( 0 to 3 ) and the percentage of cells with nuclear staining (0 to 4). Scores between 0 and 3 were defined as low, scores between 4 and 7 were defined as moderate and scores between 8 and 12 were defined as high. ALDH1 is an original marker for early differentiation of stem cells and has never been assessed in a context of tubo-ovarian dysplasia: we propose a comprehensive description according to the cellular type (epithelium/stroma), cyctoplasmic/nuclear localization, and comparing morphologic dysplastic epithelium/normal epithelium. According to Chang et $a l .{ }^{20}$ the degree of staining was quantified using a four-score grading system: cores with $<5 \%$ ALDH1- positive cells were scored as 0 , those with 5-20\% ALDH1-positive cells were scored as 1, those with 20-50\% ALDH1-positive cells were scored as 2 and those with $>50 \%$ ALDH1-positive cells were scored as 3 . For the statistical analysis, we divided cases into two groups as described by Chang et al.:20 low expression (scores between 0 and 1) and high expression (scores between 2 and 3 ).

This study was approved by the institutional review boards at the Centre Jean Perrin.

\section{Statistical analysis}

Our main measurement was the mean ovarian/tubal dysplasia score. Student's test was used to compare the dysplasia scores of the three groups. For evaluation of immunostains, nonparametric Wilcoxon statistics were applied.

\section{Results}

The comparison was made between 42 removed ovaries and tubes associated with TAM, 15 cases from the clomiphen group and 116 normal salpingo-oophorectomies with respect to morphological and immunohistochemical criteria. The indication for adnexectomy was represented in $80 \%$ and $70 \%$ of cases by the discovery of a cyst at ultrasound (respectively for group A and group B). In the remaining cases, the adnexectomy was associated with hysterectomy for metrorrhagia and/or the discovery of a thickening of the endometrium. In group $\mathrm{C}$, surgical indication was metrorrhagia and/or pelvic pain. There were only two ovarian cancers in group A and

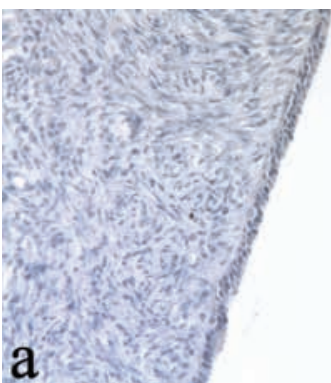

a
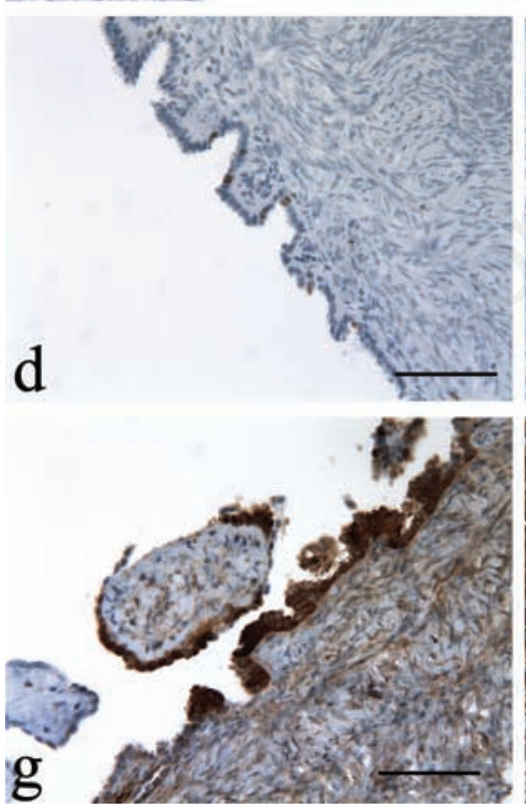

b
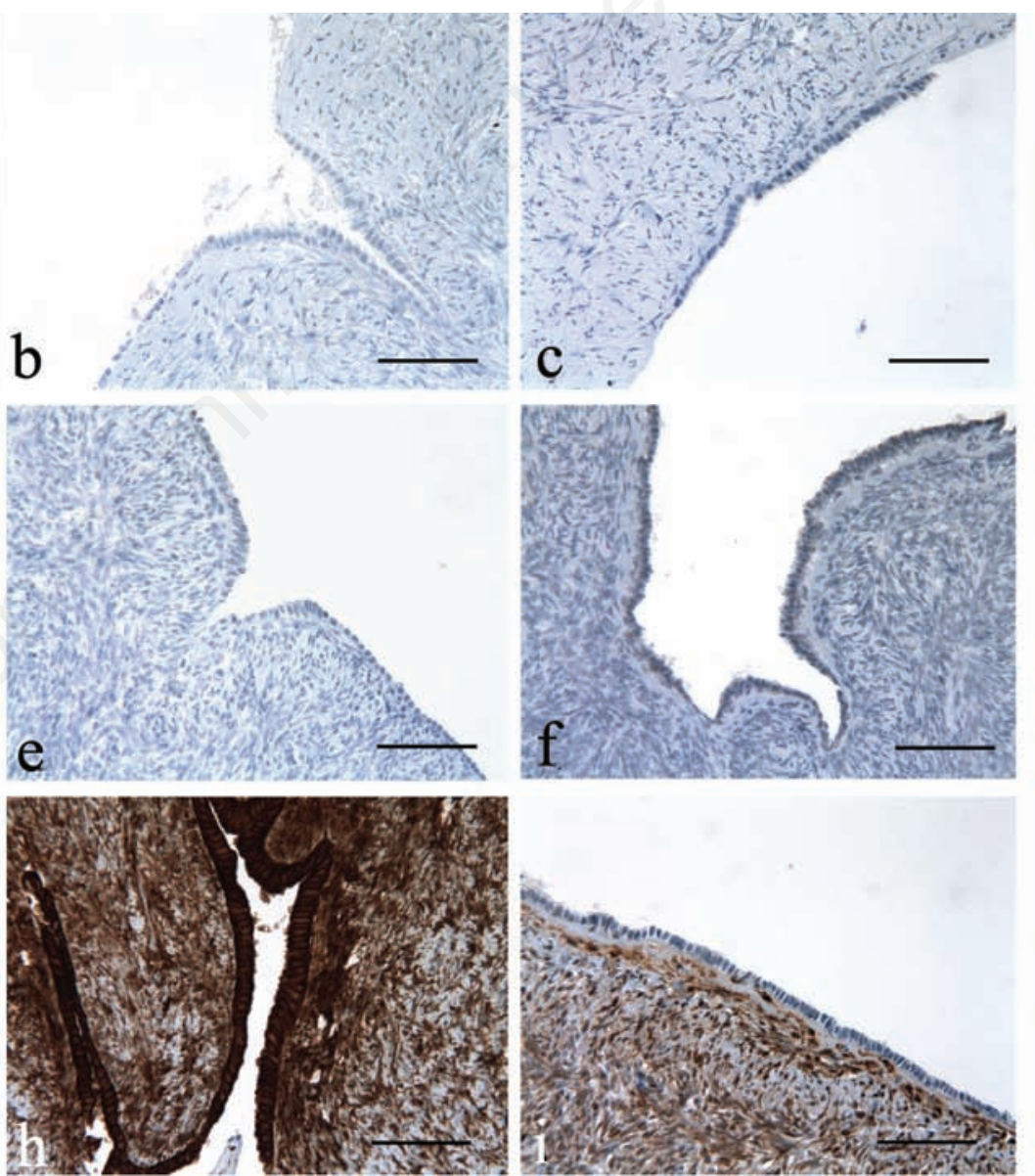

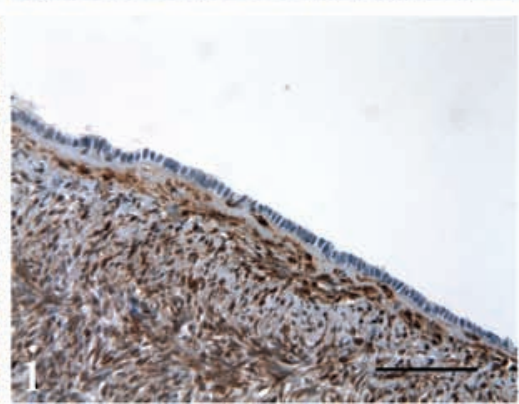

p53

Ki67

ALDH1

Figure 1. Ki67, p53 and ALDH1 immunoreactivity in ovary; left column, after treating with tamoxifen; center column, after treating with clomid; right column, untreated control group. a-c) Immunoreactivity for Ki67; note the absence of Ki67 expression in all the three representative groups. $d$-f) Immunoreactivity for p53; p53 expression is low in the ovarian epithelium exposed to tamoxifen; in contrast, there is no p53 expression in ovary exposed to clomid and in the control group. g-i) immunoreactivity for ALDH1; the expression of ALDH1 is strong in ovaries exposed to tamoxifen and clomid, whereas no immunopositivity for ALDH1 was observed in the control group; intense staining for ALDH1 was noted in stroma (internal control). 
no endometrial cancer was present. The ovarian cysts were always benign in groups A and B. All the adnexectomies were performed between 4 and 7 years after the introduction of tamoxifen.

\section{Morphological analysis}

\section{Ovarian abnormalities}

The cytological and architectural abnormalities of the ovarian epithelium described by our score were always assessed in the ovarian tissue. The histopathological abnormalities in all groups are described in Table 2. In group A, the most frequent abnormalities were represented by inclusion cysts, psammoma, epithelial pseudostratification and stromal hyperplasia. In group B, the most frequent abnormalities were represented by epithelial pseudostratification, epithelial proliferation, surface papillomatosis, cellular pleiomorphism, inclusion cysts, deep epithelial invaginations, and stromal hyperplasia. In group $\mathrm{C}$, we can note that there were $51.7 \%$ of inclusion cysts. Based on this data, a mean ovarian dysplasia score was determined for each of the three groups: 3.69 for group A, 6.5 for group B and 3.62 for the controls (no statistical difference between the three groups). Mean ovarian dysplasia score was significantly higher in the clomiphene group than in group A or in controls $(\mathrm{P}=0.009)$.

\section{Tubal abnormalities}

Cytological and architectural abnormalities of the tubal epithelium were more frequent in group A and B compared with controls. The histopathological abnormalities in all groups are described in Table 3.

Mean tubal dysplasia score was significantly higher in the TAM group and clomiphene group than in controls (respectively 7.8 vs 3.5 , $\mathrm{P}<0.007$; and 6.8 vs $3.5, \mathrm{P}=0.008$ ). No signs of salpingitis were detected in these women. Histopathological fallopian tube dysplastic changes were mainly seen in the secretory cells lining.

\section{Immunohistochemical analysis}

The expression patterns differed according to the immunohistochemical markers studied:

\section{Ovarian analysis}

Ki67 and p53 were low and infrequent in dysplastic and non-dysplastic areas in groups $\mathrm{A}$ (Figure 1a,d) and B (Figure 1b,e) compared with group $\mathrm{C}$ (Figure 1c,f) $(\mathrm{P}=0.82)$. Positivity for these two markers was found predominantly in the inclusion cysts and invaginations relative to the ovarian surface epithelium.

\section{Tubal analysis}

Expression of Ki67 and p53 appeared to be moderate in groups A (Figure 2a,d) and B (Figure 2b,e) in comparison with group $\mathrm{C}$ (Figure $2 \mathrm{c}, \mathrm{f})(\mathrm{P}=0.0047)$.

\section{ALDH1 analysis}

ALDH1 was highly expressed in the tube and ovary, in the presence of dysplasia. In non-dysplastic and in normal ovarian and tubal tissues in groups A and B, expression of ALDH1 was low and comparable to that in normal tissues of the control group (Figure 1i and Figure 2i). However, in morphologically dysplastic ovarian or tubal tissues, its expression was high and its localization was cytoplasmic. Immunohistologic fallopian tube dysplastic changes were mainly seen in the secretory cells lining. In stroma, high cytoplasmic and nuclear staining of ALDH1 was noted and thus constituted our internal control.

Noteworthy, ALDH1 expression was constantly low in the 2 carcinomas in group A (cytoplasmic staining) whereas p53 and Ki67 expression was high. Tamoxifen and clomid similarities and differences compared to the controls are shown in Figure 1g-i and Figure 2g-i, and summarized in Table 4.

\section{Discussion}

Ovarian dysplasia was initially described in ovaries with a genetic risk of cancer. ${ }^{4,5,21}$ By analogy with pre-invasive cervical lesions, the generic term dysplasia was proposed. The fact that these ovaries could evolve towards malignancy in absence of prophylactic ovariectomy led to the idea that ovarian epithelial dysplasia was the missing link prior to neoplasia. More recently, similar ovarian lesions described as

Table 3. Comparison of respective frequencies of the seven histopathologic abnormalities in our tubal dysplasia scoring system.

\begin{tabular}{|c|c|c|c|c|}
\hline Histopathological items & $\begin{array}{l}\text { Group A } \\
(n=40)\end{array}$ & $\begin{array}{c}\text { Group B } \\
(n=15)\end{array}$ & $\begin{array}{l}\text { Group C } \\
(\mathrm{n}=116)\end{array}$ & $\mathbf{P}$ \\
\hline Epithelial pseudostratification & $36(90 \%)$ & $13(86.6 \%)$ & $56(48.2 \%)$ & $\begin{array}{c}\mathrm{P} 1=0.0001 \\
\mathrm{P} 2=0.0002 \\
\mathrm{P} 3=0.82\end{array}$ \\
\hline Tufting & $32(80 \%)$ & $13(86.6 \%)$ & $13(11.2 \%)$ & $\begin{array}{l}\mathrm{P} 1<0.0001 \\
\mathrm{P} 2<0.0001 \\
\mathrm{P} 3=0.9100\end{array}$ \\
\hline Loss of nuclear polarity & $36(90 \%)$ & $12(80 \%)$ & $26(22.4 \%)$ & $\begin{array}{c}\mathrm{P} 1<0.0001 \\
\mathrm{P} 2=0.003 \\
\mathrm{P} 3=0.76\end{array}$ \\
\hline Increase in nuclear density & $35(87.5 \%)$ & $7(46.6 \%)$ & $14(12 \%)$ & $\begin{array}{c}\mathrm{P} 1<0.0001 \\
\mathrm{P} 2=0.0015 \\
\mathrm{P} 3=0.011\end{array}$ \\
\hline Nuclear atypia & $20(50 \%)$ & $12(80 \%)$ & $11(9.4 \%)$ & $\begin{array}{c}\mathrm{P} 1<0.0001 \\
\mathrm{P} 2<0.0001 \\
\mathrm{P} 3=0.021\end{array}$ \\
\hline Nucleomegaly & $34(85 \%)$ & $10(66.6 \%)$ & $14(12 \%)$ & $\begin{array}{c}\mathrm{P} 1<0.0001 \\
\mathrm{P} 2<0.0001 \\
\mathrm{P} 3=0.12\end{array}$ \\
\hline Loss of ciliation & $34(85 \%)$ & $12(80 \%)$ & $7(6 \%)$ & $\begin{array}{c}\mathrm{P} 1<0.0001 \\
\mathrm{P} 2<0.0001 \\
\mathrm{P} 3=0.89\end{array}$ \\
\hline
\end{tabular}

P1, statistical differences between group A and C; P2, statistical differences between group B and C; P3, statistical differences between group $A$ and $B$.

Table 4. Tamoxifen and clomid similarities and differences.

\begin{tabular}{lccc} 
& Group A: TAM & Group B: Clomid & Group C: Control \\
Ovarian dysplasia score & 3.69 & 6.5 & 3.62 \\
Ovarian Ki67 expression & Low & Low & Low \\
\hline Ovarian p53 expression & Low & Low & Low \\
Ovarian ALDH 1 expression & High & High & Low \\
\hline Tubal dysplasia score & 7.8 & 6.8 & 3.5 \\
Tubal Ki67 expression & Moderate & Moderate & Low \\
Tubal p53 expression & Moderate & Moderate & Low \\
Tubal ALDH1 expression & High & High & Low \\
\hline
\end{tabular}

TAM, tamoxifen. 
dysplasia were detected in ovaries stimulated during in vitro fertilization (IVF) treatment. Nieto et al. ${ }^{12}$ firstly found significant abnormalities in stimulated ovaries compared to a control population. Our previous studies confirmed these results (mean dysplasia score 7.64) and ovarian dysplasia seemed to be linked to the intensity and number of stimulations (dose-effect) and after a sufficient lapse of time (time-effect). ${ }^{13}$ However, the long term evolution is unknown. ${ }^{14,22}$ Animal experiments have given some interesting conclusions. Ovulation in rats resulted in dysplastic abnormalities in the ovarian epithelium with a relationship between the number of induced ovulation cycles and the severity of ovarian dysplasia. ${ }^{23-26}$ Tamoxifen has a clomid-like effect and has sometimes been used in ovulation stimulation protocols. ${ }^{1,2}$ In addition, the deleterious effects of tamoxifen on the endometrium, such as endometrial polyps, endometrial carcinoma and endometrial hyperplasia ${ }^{27,28}$ are now wellknown. However, results about the relationship between ovarian cancers and tamoxifen are contradictory: in some studies, tamoxifen treatment for breast cancer does not appear to increase the risk of ovarian cancer, ${ }^{29,30}$ whereas other studies have indicated ovarian cancer arising with prolonged use of Tamoxifen. ${ }^{31,32}$ We found few morphological ovarian abnormalities in TAM group whereas there were more abnormalities in ovaries associated with clomiphen; Madhavi et al. ${ }^{22}$ proposed in his recent review a possible causal link between induction of ovulation and ovarian tumors because clomiphen appear to increase the risk of borderline ovarian tumors.

Results in tubal dysplasia associated with the administration of TAM or clomiphen are very interesting because of the similar profiles. It is true that the link between cause and effect is difficult to establish since these patients had all had breast cancer for which this hormone therapy was the final treatment. However, all the adnexectomies took place after at least four years of tamoxifen use; except for two patients excluded from the dysplasia scoring analysis, no patient had a BRCA 1 or 2 mutation and no patient had any other cancer with an epidemiological connection. The literature reports only two cases of bilateral atypical tubal hyperplasia in tamoxifentreated women. ${ }^{33}$ Hyperplasia of the oviduct has also been described in female offspring of CD-1 mice that were prenatally exposed to tamoxifen. ${ }^{34}$. An even more recent animal study found ovarian dysplasia in female rats given tamoxifen but the slight increase in dysplasia was not significant: the authors raised the question of a longer duration of Tamoxifen administration. ${ }^{35}$ Another animal study found histopathological dysplasia in ovaries and tubes exposed to tamoxifen with a high Ki67

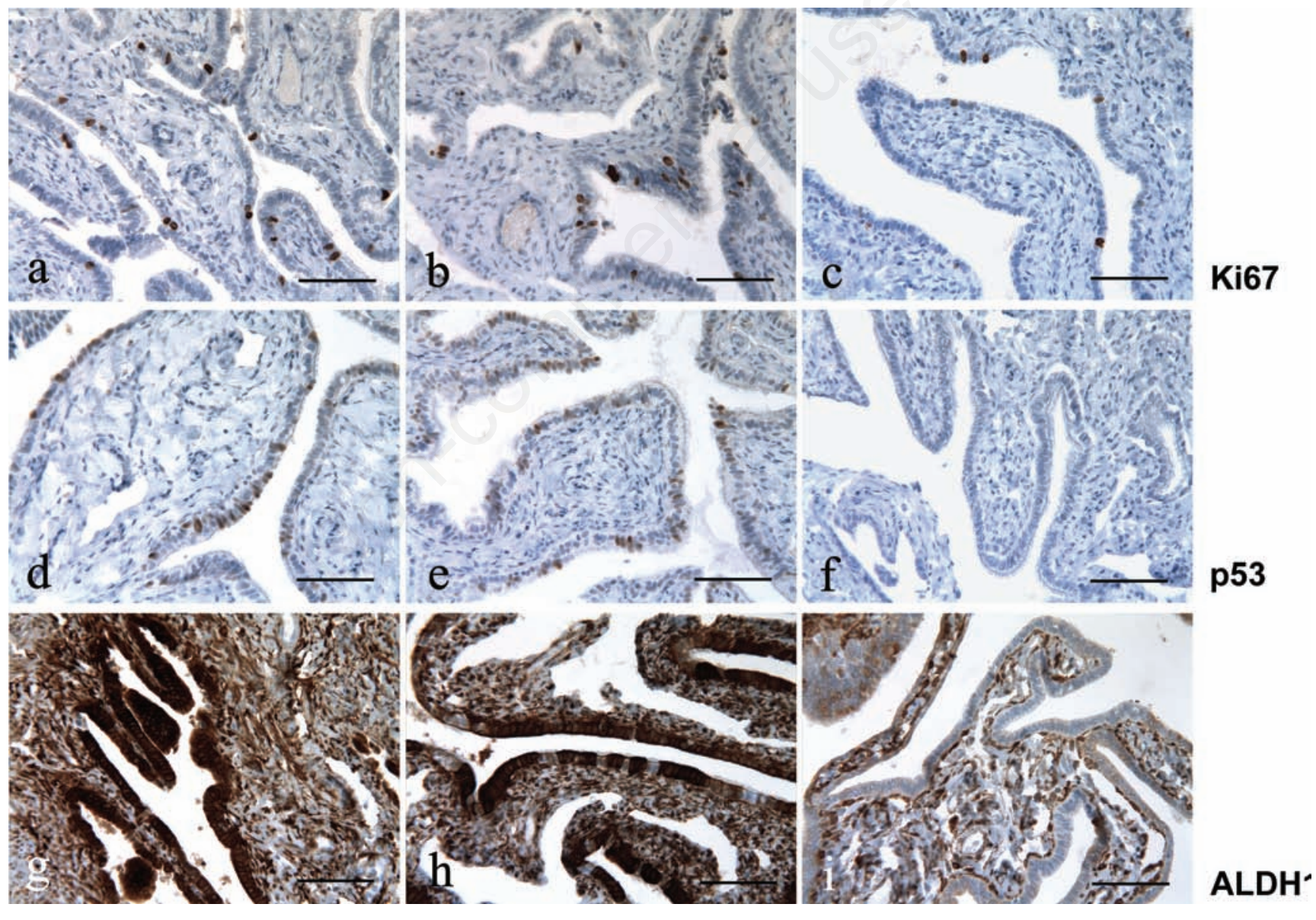

Figure 2. Ki67, p53 and ALDH1 immunoreactivity in fallopian tube; left column, after treating with tamoxifen; center column, after treating with clomid; right column, untreated control group. a-c) Immunoreactivity for Ki67; note the moderate expression of Ki67 in the tubes exposed to tamoxifen and clomid, and the low expression in the control group. d-f) Immunoreactivity for p53; the expression of p53 is weak in the tubes exposed to tamoxifen and clomid, and not present in the control group. g-h) ALDH1 immunoreactivity; note the strong expression of ALDH1 in the tubes exposed to tamoxifen and clomid, and the low or absent expression in the control group; also note the on/off effect of ALDH1 expression in panel h, where ALDH1 is mainly detected in the secretory cells lining but not in the ciliated cells. Scale bars: $100 \mu \mu \mathrm{m}$. 
expression and a low p53 expression. ${ }^{36}$ Moreover, these results raise the question of the pathogenesis of tubo-ovarian carcinogenesis. More recently, during systematic histopathological examination of tissues from prophylactic adnexectomies for a genetic risk, the revelation of occult tubal cancer (about $10 \%$, and between 50 and nearly $100 \%$ of these cases have exhibited involvement of the fimbriated end of the fallopina tube) gave rise to the postulate of a tubal origin for ovarian cancer. $^{37-41}$ In view of these results, the combination of a systemic oestrogenic effect with the clomid-like effect of tamoxifen could be evoked on the epithelium of the tubes (such as in the ndometrium). ${ }^{42}$

The immunohistochemical study added an extra-parameter for describing tubo-ovarian dysplasia. The two immunohistochemical markers p53 and Ki67 are described as being significantly expressed in ovarian cancer tissues compared with controls. The postulate that these markers would be expressed in dysplastic tissues could thus confirm their preinvasive nature. Schlosshauer et al. ${ }^{19}$ found in their study a gradual increase in immunoreactivity comparing normal ovarian epithelium (lowest expression), dysplastic epithelium (stronger expression) and ovarian cancer (highest expression), which would represent a molecular argument for the existence of dysplasia. Concerning tubal dysplasia, Piek et al. ${ }^{18}$ found distinct expression of these two markers in dysplastic tubes. In our study, expression of Ki67 and p53 appeared to be weak in ovaries whereas they were more marked in tubes of groups A and B: this could be another argument for the importance of tubes in the tuboovarian dysplasia pathogenesis. Histopathological and immunohistochemical fallopian tube dysplastic changes were mainly seen in the secretory cells lining, as they are the potential significant precursors of tubal and ovarian cancer. Last but not the least, the originality of our study also lies in the assessment of the marker for early stem cell differentiation, ALDH1. Several scientific proofs could support the cancer stem cell hypothesis for which some human cancers could originate in tissue stem and/or progenitor cells. ${ }^{43}$ The true function of ALDH1 is not well known and could involve in early stem cell differentiation. The high ALDH1 expression in normal human and mouse ovary, its potential role in cancer stem cells in other tumors (especially breast cancer where it may be a predictor of poor clinical outcome) suggest that ALDH1 could have an implication in ovarian tumors. This enzyme is involved in the metabolism of retinoic acids, which plays an important role in regulation of pathways like AKT/ $\beta$-cathénine, WNT, p21/p53. ${ }^{44-48}$

Immunohistochemical staining of ALDH1 expression was analysed in 442 primary ovarian carcinoma. ${ }^{20}$ Unlike the case for breast cancer, ALDH1 would be a favourable prognostic factor in ovarian carcinoma because high expression was significantly associated with early-stage disease $(\mathrm{P}=0.006)$. In another study, ALDH1 expression and enzyme activity were lower in malignant ovarian tumors. ${ }^{48}$ ALDH1 expression was constantly low in the 2 carcinomas of our study. The expression of ALDH1 appears to be exclusively found and strongly expressed in dysplastic ovarian and tubal epithelia. ALDH1 may have a different function in ovarian cancer than it does in breast cancer, where it is usually overexpressed. ${ }^{49-51}$ We found a similar expression of ALDH1 in a series of prophylactic ovariectomies for BRCA mutations (unpublished results). ALDH1 seems to have a on/off effect (overexpression in dysplasia area) and may be highly restricted to epithelial tubal dysplasia and could be help in their identification (Figure 1c). Auersperg et al. ${ }^{52}$ recently compared the stem-cell profile of ovarian surface epithelium and fallopian tube with 5 stem-cell markers (NANOG, SFRP1, LHX9, ALDH1A1 and ALDH1A2). The authors found that ALDH1 was significantly increased in ovarian inclusion cysts and in the distal parts of the fallopian tube. They concluded that ovarian surface epithelium and tubal epithelium may have the capacity to undergo neoplastic transformation. Another study with different stem-cell markers (epithelial cell adhesion molecule, CD44, integrin a6) confirmed that stem cells are located in the distal end of the fallopian tubes. ${ }^{53}$ However, the exact meaning and the mechanism of this strong expression remain to be investigated, and further studies are necessary.

\section{Conclusions}

This morphological and immunohistochemical study found significant dysplastic epithelial lesions in a series of adnexectomy tissues in women exposed to tamoxifen. One of the possible clinicopathological explanations would be the combination of a systemic oestrogenic effect with the clomid-like effect of tamoxifen. However, the reason why the lesions are predominantly found in the tubes rather than in the ovaries remains questionable. This could point out the importance of the newly tubal theory of ovarian carcinogenesis. There are many elements of bias that could make the involvement of tamoxifen in the genesis of the dysplasia debatable. However, these results could encourage a fully comprehensive pathological analysis of adnexectomy tissues to be carried out for all patients with tamoxifen exposure. ${ }^{54}$

\section{References}

1. Brown J, Farquhar C, Beck J, Boothroyd C, Hugues E. Clomiphene and anti-oestrogens for ovulation induction in PCOS. Cochrane Database Syst Rev 2009;4: CD002249.

2. Badawy A, Gibreal A. Clomiphene citrate versus tamoxifen for ovulation induction in women with PCOS : a prospective randomized trial. Eur J Obstet Gynecol Reprod Biol 2011;159:151-4.

3. Salazar H, Godwin AK, Daly MB, Laub PB, Hogan M, Rosenblum N, et al. Microscopic benign and invasive malignant neoplasms and a cancer-prone phenotype in prophylactic oophorectomies. J Natl Cancer Inst 1996;88:1810-20.

4. Werness BA, Afify AM, Bielat KL, Eltabbakh GH, Piver MS, Paterson JM. Altered surface and cyst epithelium of ovaries removed prophylactically from women with a family history of ovarian cancer. Hum Pathol 1999;30:151-7.

5. Stratton JF, Buckey CH, Lowe D, Ponder BAJ. Comparison of prophylactic oophorectomy specimens from carriers and non carriers of a BRCA1 or BRCA2 gene mutation. J Natl Cancer Inst 1999;91: 626-8.

6. Resta L, Russo S, Colucci GA, Prat J. Morphologic precursors of ovarian epithelial tumors. Obstet Gynecol 1993;82:181-6.

7. Plaxe S, Deligdish L, Dottino P, Cohen C. Ovarian intraepithelial neoplasia demonstrated in patients with stage I ovarian carcinoma. Gynecol Oncol 1990;38:67-72.

8. Mittal KR, Jacquotte AZ, Cooper JL, Demopoulos R. Controlateral ovary in unilateral ovarian carcinoma: a search for preneoplastic lesions. Int J Gynecol Patho 1993;12:59-63.

9. Tressera F, Grases PJ, Labastida R, Ubeda A. Histological features of the controlateral ovary in patients with unilateral ovarian cancer: a case control study. Gynecol Oncol 1998;71:437-41.

10. Chene G, Rahimi K, Mes Masson AM, Provencher D. Surgical implications of the potential new tubal pathway for the ovarian carcinogenesis. J Minim Invasive Gynecol 2013;20:153-9.

11. Carcangiu ML, Radice P, Manoukian S, Spatti G, Gobbo M, Pensotti V, et al. Atypical epithelial proliferation in Fallopian tubes in prophylactic salpingooophorectomy specimens from BRCA 1 and BRCA 2 germline mutation carriers. Int J Gynecol Pathol 2003;23:35-40.

12. Nieto JJ, Crow J, Sundaresan M, Constantinovici N, Perret CW, Mc Lean AN, Hardiman PJ. Ovarian epithelial dysplasia in relation to ovulation induction and nul- 
liparity. Gynecol Oncol 2001;82:344-9.

13. Chene G, Penault-Llorca F, Le Bouedec G, Mishellany F, Dauplat MM, Jaffeux P et al. Ovarian epithelial dysplasia after ovulation induction: time and dose effect. Human Reprod 2009;24:132-8.

14. Chene G, Dauplat J, Radosevic-Robin N, Cayre A, Penault-Llorca F. Tu-be or not tube: that is the question...about serous ovarian carcinogenesis. Crit Rev Oncol Hematol 2013;88:134-43.

15. Chene G, Dauplat J, Raoelfils I, Bignon YJ, Cayre A, Jaffeux P, et al. Ovarian epithelial dysplasia: Description of a dysplasia scoring scheme. Ann Pathol 2011;31:3-10.

16. Chene G, Raoelfils I, Cayre A, Dauplat J, Bignon YJ, Jaffeux P, et al. Don't forget fallopian tubes! A morphologic and immunohistochemical study about Fallopian tubes with genetic risk (BRCA mutation). Gynecol Obstet Fertil 2012;40:14-8.

17. Yanai-Inbar I, Siriaunkgul S, Silverberg SG. Mucosal epithelial proliferation of the fallopian tube: a particular association with ovarian serous tumor of low malignant potential? Int J Gynecol Pathol 1995;14:107-13.

18. Piek JM, van Diest PJ, Zweemer RP. Dysplastic changes in prophylactic removed fallopian tubes of women predisposed to developping ovarian cancer. J Pathol 20012001 ; 195 : 451-6.

19. Schloosshauer PW, Cohen CJ, PenaultLllorca F, Miranda CR, Bignon YJ, Dauplat $\mathrm{J}$, et al. Prophylactic oophorectomy. Cancer 2003;98:2599-606.

20. Chang B, Liu G, Xue F, Rosen DG, Xiao L, Wang X, et al. ALDH1 expression correlates with favorable prognosis in ovarian cancers. Modern Pathol 2009;22:817-23.

21. Deligdish L, Gil J, Kerner H, Wu HS, Beck D, Gershoni-Baruch R. Ovarian dysplasia in prophylactic oophorectomy specimens: cytogenetic and morphometric correlations. Cancer 1999;86:1544-50.

22. Mahdavi A, Pejovic T, Nezhat F. Induction of ovulation and ovarian cancer: a critical review of the literature. Fertil Steril 2006;85:819-26.

23. Corakci A, Filiz S, Caliskan E, Dalcik C, Ozeren S, Dalcik H. The effects of ovulation induction on ovarian epithelium dysplasia scores and Ki67 expression: an experimental study on rats. Int J Gynecol cancer 2005;15:866-71.

24. Celik C, Gezginc K, Aktan M, Acar A, Yaman ST, Gungor S, et al. Effects of ovulation induction on ovarian morphology: an animal study. Int $\mathrm{J}$ Gynecol Cancer 2004;14:600-6.

25. Ozcan Z, Celik H, Gurates B, Ozercan HI, Nanay F, Nalbant M, et al. Effects of ovulation induction agents on ovarian surface epithelium in rats. Reprod Biomed Online 2009;19:314-18.

26. Lacoste CR, Clemenson A, Lima S, Lecointre R, Peo'ch M, Chene G. Tuboovarian dysplasia in relatioship with ovulation in rats. Fertil Steril 2013;99:1768-73.

27. Williams-Brown MY, Salih SM, Xu X, Veenstra TD, Saeed M, Theiler SK, et al. The effect of tamoxifen and raloxifen on estrogen metabolism and endometrial cancer risk. J Steroid Mol Biol 2011;126:78-86.

28. Neri F, Maggino T. Surveillance of endometrial pathologies, especially for endometrial cancer, of breast cancer patients under tamoxifen treatment. Eur J Gynaecol Oncol 2009;30:357-60.

29. Vicus D, Rosen B, Lubinski J, Domchek S, Kauff ND, Lynch HT, et al. Tamoxifen and the risk of ovarian cancer in BRCA1 mutation carriers. Gynecol Oncol 2009;115:1357.

30. Swerdlow AJ, Jones ME. Ovarian cancer risk in premenopausal and perimenaopausal women treated with Tamoxifen: a case-control study. $\mathrm{Br} \mathrm{J}$ Cancer 2007;96:850-5.

31. Cohen I, Beyth Y, Tepper R, Shapira J, Zalel Y, Figer A, et al. Ovarian tumors in postmenopausal breast cancer patients treated with tamoxifen. Gynecol Oncol 1996;60:54-8.

32. Lavie 0, Longacre T, Segev Y, Husain A. Ovarian carcinosarcomas associated with prolonged use of tamoxifen: case reports. Int J Gynecol Cancer 2009;19:1521-3.

33. Pickel H, Reich 0, Tamussino K. Bilateral atypical hyperplasia of the fallopian tube associated with tamoxifen : a report of two cases. Int J Gynecol Pathol 1999;17:284-5.

34. Diwan BA, Anderson LM, Ward JM. Proliferative lesions of oviduct and uterus in CD-1 mice exposed prenatally to tamoxifen. Carcinogenesis 1997;18:2009-14.

35. Ting AY, Kimler BF, Fabian CJ, Petroff BK. Tamoxifen prevents premalignant changes of breast, but not ovarian cancer in rats at high risk for both diseases. Cancer Prev Res 2008;1:546-53.

36. Lima S, Clemenson A, Trombert B, Lecointre R, Lacoste CR, Peo'ch M, et al. Morphological and immunohistochemical analysis in ovaries and tubes of tamoxifen, letrozole and clomifene-treated rats. Arch Gynecol Obstet 2014; in press.

37. Folkins AK, Jarboe EA, Saleemuddin A, Lee Y, Callahan MJ, Drapkin R, et al. A candidate precursor to pelvic serous cancer (p53 signature) and their prevalence in ovaries and fallopian tubes from women with BRCA mutations. Gynecol oncol 2008;109:168-73.

38. Crum CP, Drapkin R, Kindelberger D,
Medeiros F, Miron F, Lee Y. Lessons from BRCA: the tubal fimbria emerges as an origin for pelvic serous cancer. Clin Med Res 2007;5:35-44.

39. Powell CB, Kenley E, Chen LM, Crawford B, McLennan J, Zaloudek C, et al. Riskreducing salpingo-oophorectomy in BRCA mutation carriers: role of serial sectioning in the detection of occult malignancy. $\mathbf{J}$ Clin Oncol 2005;23:127-32.

40. Finch A, Shaw P, Rosen B, Murphy J, Narod SA, Colgan TJ. Clinical and pathologic findings of prophylactic salpingooophorectomies in 159 BRCA1 and BRCA2 carriers. Gynecol Oncol 2006;100:58-64.

41. Nik NN, Vang R, Shih IM, Kurman RJ. Origin and pathogenesis of pelvic (ovarian, tubal, and primary peritoneal) serous carcinoma. Annu Rev Pathol 2014;9:27-45.

42. Emons G, Fleckenstein G, Hinney B, Huschmand A, Heyl W. Hormonal interactions in endometrial cancer. Endoc Relat Cancer 2000;7:227-42.

43. Ponnusamy MP, Batra SK. Ovarian cancer: emerging concept on cancer stem cells. J Ov Research 2008;4:1-9.

44. Liu S, Ginestier C, Charafe-Jauffret E, Foco H, Kleer CG, Merajver SD, et al. BRCA1 regulates human mammary stem/progenitor cell fate. Proc Natl Acad Sci USA 2008;105:1680-85.

45. Ginestier C, Wicinski J, Cervera N, Monville F, Finetti P, Bertucci F, et al. Retinoid signaling regulates breast cancer stem cell differentiation Cell Cycle 2009;8: 3297-302.

46. Heerma van Voss MR, Van der Groep P, Bart Joost, Van der Wall E, Van diset PJ. Expression of the stem cell marker ALDH1 in the normal breast of BRCA1 mutation carriers. Breast Cancer Res Treat 2010; 123:611-2.

47. Ginestier C, Hur MH, Charafe-Jauffret E, Monville F, Dutcher J, Brown M, et al. ALDH1 is a marker of normal and malignant human mammary sterm cells and a predictor of poor clinical outcome. Cell Sterm Cell 2007;1:555-67.

48. Penumatsa K, Edassery SL, Barua A, Bradaric MJ, Luborsky JL. Differential expression of aldehyde dehydrogenase 1a1 (ALDH1) in normal ovary and serous ovarian tumors. J Ov Research 2010;28:1-13.

49. Charafe-Jauffret E, Ginestier C, Iovino F, Tarpin C, Diebel M, Esterni B, et al. Aldehyde dehydrogenase 1 positive cancer stem cells mediate metastasis and poor clinical outcome in inflammatory breast cancer. Clin Cancer Res 2010;16:45-55.

50. Deng S, Yang X, Lassus H, Liang S, Kaur S, Ye $Q$ et al. Distinct expression levels and atterns of sterm cell marker, Aldehyde Dehydrogenase Isoform 1 (ALDH1), in 
human epithelial cancers. Plos One 2010;5:e10277.

51. Kryczek I, Liu S, Roh M, Vatan L, Szeliga W, Wei S et al. Expression of aldehyde dehydrogenase and CD133 defines ovarian cancer stem cells. Int J Cancer 2012;130:29-39.

52. Auersperg N. The stem-cell profile of ovarian surface epithelium is reproduced in the oviductal fimbriae, with increased stem-cell marker density in distal parts of the fimbriae. Int $\mathrm{J}$ Gynecol Pathol 2013;32:444-53.

53. Paik DY, Janzen DM, Schafenacker AM, Velasco VS, Shung MS, Cheng D, et al. Stem-like epithelial cells are concentrated in the distal end of the fallopian tube: a site for injury and serous cancer initiation. Stem cells 2012;30:2487-97.

54. Chene G, Penault-Llorca F, Le Bouedec G, Mishellany F, Dauplat MM, Jaffeux P, et al. Ovarian epithelial dysplasia and prophylactic oophorectomy for genetic risk. Int $\mathbf{J}$ Gynecol Cancer 2009;19:65-72. 